\title{
EDUCAÇÃO JURÍDICA PARA O BEM VIVER: A SUPERAÇÃO DE UM ARQUÉTIPO EUROCÊNTRICO PARA UMA EPISTEMOLOGIA DO SUL
}

\author{
Maria Aparecida Lucca Caovilla ${ }^{\mathrm{i}}$ \\ Manoel Boita ${ }^{\text {ii }}$ \\ Carmelice Faitão Balbinot ${ }^{\text {iii }}$
}

\begin{abstract}
Resumo: Este artigo aborda aspectos da colonialidade do ser, do saber e do poder no contexto latino-americano, contestando a lógica tradicional do ensino e da educação transmissiva, em especial ao modelo de ensino jurídico. Discute, ainda, a necessidade de descolonização da cultura no ensino do Direito, considerando a importância de educar para múltiplas sabedorias, criatividades expressivas e reflexivas, integrantes da cultura latino-americana. Para dar conta de atender a estas inquietações, pergunta-se: será possível um novo modelo de educação no Direito, fundamentado na efetivação da cidadania, da democracia e de justiça para o bem viver no continente latino-americano? Intenta-se um novo caminho à educação jurídica na América Latina, com o propósito de renovar o processo de construção dos saberes, calcado nas necessidades da sociedade, para o rompimento da burocratização, formalismo, positivismo e individualismo nas práticas jurídicas no Brasil, ancorado no pluralismo jurídico comunitário-participativo.
\end{abstract}

Palavras-chave: Educação intercultural; Bem Viver; Colonialidade; Descolonização.

\section{EDUCACIÓN JURÍDICA PARA EL BUEN VIVIR: LA SUPERACIÓN DE UN ARQUÉTIPO EUROCÉTRICO PARA UNA EPISTEMOLOGÍA DEL SUR}

\begin{abstract}
Resumen: Este artículo aborda aspectos de la colonialidad del ser, del saber y del poder en el contexto latinoamericano, contestando la lógica tradicional de la enseñanza y la educación transmisiva, en especial al modelo de enseñanza jurídica. En el caso de la cultura latinoamericana, se debe tener en cuenta la importancia de educar para múltiples sabidurías, creatividades expresivas y reflexivas, integrantes de la misma. Para dar cuenta de atender a estas inquietudes, se pregunta: ¿será posible un nuevo modelo de educación en el Derecho, fundamentado en la efectividad de la ciudadanía, la democracia y la justicia para el buen vivir en el continente latinoamericano? Se trata de un nuevo camino a la educación jurídica en América Latina, con el propósito de renovar el proceso de construcción de los saberes, basado en las necesidades de la sociedad, para el rompimiento de la burocratización, formalismo, positivismo e individualismo en las prácticas jurídicas en Brasil, anclado en el pluralismo jurídico comunitario-participativo.
\end{abstract}

Palabras clave: Educación intercultural; Buen Vivir; Colonialidad; Descolonización. 


\section{Introdução}

Desde a chegada dos europeus, no final do século XV, diversos agrupamentos multiétnicos permanecem às margens da estrutura político-social adotada no continente latino-americano. $\mathrm{Na}$ trajetória dos povos originários latino-americanos uma série de injustiças históricas são marcadas pela colonização, despossessão de terras, territórios e recursos, opressão e discriminação, negação de culturas, a serviço de um suposto desenvolvimento, entendido como crescimento econômico a qualquer custo.

Desde o "descobrimento" da América Latina "tudo", quer dizer, a terra e o que dela provêm, os homens, sua força de trabalho e seu potencial de consumo, se [...] transformou em capital europeu ou, mais tarde, norte-americano, e como tal tem-se acumulado e se acumula até hoje nos distantes centros de poder (GALEANO, 2010, p. 18).

Os critérios eurocêntricos, utilizados para esse fim, lograram ares de universalidade com a afirmação da modernidade como projeto supostamente mundial, desprezando e desqualificando outras epistemologias, se fechando a outras culturas, outras línguas, outras identidades, outras lógicas para construir e afirmar um mundo de pensamento único.

Sobre a iniquidade dessa realidade, Fanon (1968, p. 175), em sua obra "Os Condenados da Terra", diz que o colonialismo não se contenta em impor seu domínio [...] não basta encerrar o povo em suas malhas, esvaziar o cérebro colonizado de toda a forma e conteúdo [...] ele se orienta para o passado do povo oprimido, o distorce, desfigura e destrói.

E o colonialismo, destaca Larrea (2010), não terminou com a independência dos países latino-americanos. As diversidades sempre foram consideradas obstáculos ao progresso e, por essa razão, foram sujeitas a um processo de homogeneização, subalternizadas por supostamente não terem potencial político para participar do processo de independência dos países.

De acordo com Castro-Gómez (2005), a colonialidade se desenvolve em eixos de poder, de saber e do ser, referindo-se à produção de um conhecimento essencialmente hegemônico. A colonialidade persiste e é evidente em diversos contextos, entre eles: o cultural, em que são enaltecidos ícones europeus e norte-americanos; o econômico, sendo as populações mais pobres aquelas que foram historicamente objetificadas no processo de colonização; e o político, com falta de representatividade dessas minorias. Nesse processo, ocorre uma aculturação e os valores e princípios originários são substituídos por novos que carecem de identificação com a realidade local (CAOVILLA; WENGENOVICZ, 2018). 
A colonialidade do ser se refere, assim, à não existência e à desumanização, uma negação do status do ser humano, iniciada dentro dos sistemas de cumplicidade do colonialismo e escravidão (WALSH, 2007, p. 29). No que se refere ao saber, a colonialidade nega as epistemes próprias em razão da imposição de outra, eurocêntrica, monista, limitada e limitante, ainda que esta não seja capaz de abarcar todas as diversas realidades existentes quando, em verdade, há uma diversidade epistêmica que comporta todo o patrimônio da humanidade acerca da vida, das águas, da terra, do fogo, do ar, dos homens (PORTOGONÇALVES, 2005, p. 3).

A colonialidade do poder, do ser e do saber é, portanto, uma outra dimensão da Modernidade. Trata-se de sua face obscura (TLOTSTANOVA; MIGNOLO, 2009) que se destina a dominação social e a formação de um padrão de poder universal que o Direito regula.

Mignolo (2008), em dado momento resgata a primeira descolonização iniciada no século XIX, ressaltando a sua incompletude, eis que tratou de cuidar, apenas, da independência política das periferias coloniais. Um sinal importante da força social comunitária de organização política e jurídica própria e de opção descolonial dos movimentos sociais na América Latina.

Na contemporaneidade, o exercício de direitos e, consequentemente, da cidadania, são um exemplo emblemático de como a manutenção da matriz colonial consolidou um modelo de desenvolvimento desigual, suprimindo os saberes tradicionais, explorando de maneira desmedida os recursos naturais, subjugados à uma epistemologia ditada pelos países ocidentais.

\section{A necessária superação de um modelo - para uma epistemologia do Sul}

A construção de uma sociedade livre, verdadeiramente, desenhada e harmonizada com novas formas de conhecimento que respeitam a realidade humana latino-americana, sustentase na elaboração de um conhecimento crítico e emancipador do Sul, reiterando as experiências que até hoje foram transformadas pelo e com o pensamento hegemônico.

É preciso "sulear" e, mais do que isso, "aprender a buscar o Sul", como forma de contrariar a lógica dominante eurocêntrica no qual o "norte" é apresentado como referência universal. Paulo Freire sugeriu "deixar de nortear" e passar a "sulear". Mas ele foi mais longe: disse que o caminho teria que ser da interdependência, em que um não pode ser se o outro não é (FREIRE, 2003, p. 232). 
A direção a ser tomada parte do Sul, de uma epistemologia pura, que não seria mais de um pensamento que se propõe a conhecer para dominar, mas o de conferir sentido à perene transformação social que já vem acontecendo em todo o continente (CAOVILLA, 2016, p. 128).

Essa perspectiva emerge da América Latina, pelos movimentos emancipatórios de um constitucionalismo pluralista, que para Fajardo (2016, p. 120): reconhece a existência da realidade de diversidade ou pluralidade cultural, linguística, jurídica das sociedades e a eleva ao princípio constitucional e direito, tanto individual como coletivo e trata-se de uma leitura realizada por meio de uma epistemologia diferente da perspectiva eurocêntrica, ou seja, começa a nascer uma epistemologia do Sul, que reconhece a interculturalidade e o caráter ilusório do Estado.

Esta epistemologia do Sul impõe o reconhecimento de um "giro", ao constitucionalismo liberal-democrático, vislumbrando em um outro extremo, a sustentabilidade de diferentes tradições jurídicas (CARDUCCI; AMAYA, 2016). Assim, fazse necessário fortalecer a pluralidade epistêmica, propondo uma visão de mundo socioambientalmente justa, sustentável, intercultural, inclusiva e democrática. Para tanto, o uso de outras metodologias podem refletir os anseios de nossa própria existência e experiências, e nos dar condições de revelar a originalidade e a identidade do 'ser' latinoamericano.

\section{O ensinamento dos povos originários do Sul para descolonizar a educação}

Os Estados coloniais e modernos, no afã do crescimento econômico, sonegam direitos e como resultado disto, os povos originários, se convertem em grupos empobrecidos. Essa realidade levou a consolidação de uma desigualdade abissal, contexto no qual os dilemas econômicos e socioambientais afligem de maneira muito mais gravosa as populações marginalizadas, como é o caso dos indígenas, descendentes dos povos originários.

Tais comunidades foram, por muito tempo, silenciadas e tiveram sua participação política e social desmerecida. Entretanto, a proposta do constitucionalismo que desponta dos Andes, especialmente com as constituições do Equador (2008) e da Bolívia (2009), é exemplo de uma experiência autenticamente latino-americana e, com o reconhecimento dos direitos de Pachamama (Terra) e a cultura do Bem Viver, inaugura um novo ciclo civilizatório rompendo com aquele imposto na modernidade, buscando alternativas ao desenvolvimento e ao Direito convencional (CAOVILLA, 2016). 
A civilização moderna tem se esquecido que a natureza é fonte de vida, que todos os seres humanos dependem dela para sua sobrevivência e que a multiplicidade de crises vivenciadas pelas sociedades é pressuposto do desenvolvimento econômico, que ignora os recursos naturais e sociais, os quais interpretam o planeta como uma fonte inesgotável de recursos (SIDEKUM; WOLKMER; RADAELLI, 2016).

Milhares de iniciativas populares estão brotando "desde baixo", entre elas, as práticas do Bem Viver, própria dos povos indígenas dos Andes, que nos apresentam elementos fundamentais para uma nova civilização, pois estabelece uma convivência comunitária intercultural e sem assimetrias de poder (CAOVILLA, 2016).

[...] vem dos povos originários uma proposta que poderá ser inspiradora de uma nova civilização focada no equilíbrio e na centralidade da vida. O ideal que propõem é o bem-viver (sumak kausay ou suma qamaña). $\mathrm{O}$ 'bem viver' não é o nosso 'viver melhor' ou 'qualidade de vida' que, para se realizar, muitos têm que viver pior e ter uma má qualidade de vida. $\mathrm{O}$ bem viver andino visa uma ética da suficiência para toda a comunidade e não apenas para o indivíduo. Pressupõe uma visão holística e integradora do ser humano inserido na grande comunidade terrenal que inclui, além do ser humano, o ar, a água, os solos, as montanhas, as árvores e os animais, o Sol, a Lua e as estrelas; é buscar um caminho do equilíbrio e estar em profunda comunhão com a Pacha (a energia universal) que se concentra na Pachamama (Terra), com as energias com universo e com Deus (BOFF, 2013, p. 61-62).

O Bem Viver propõe um novo modo de vida, uma proposta fundamentada em diferentes posturas, na busca de uma cultura em atitude de respeito e reciprocidade com todo o universo, apontando para a construção de um outro mundo: um mundo onde caibam todos os mundos, edificando a vontade dos Zapatistas. Este outro mundo não é apenas ilusão ou utopia, será possível para quem o quer construir, contudo, precisa ser coletivo. Construir uma outra sociedade, com todas as características do Bem Viver, exige muita vontade, criatividade e principalmente, novas ações.

Moraes (2014) destaca a importância da participação indígena no processo constituinte democrático que promoveu o giro ecocêntrico, comunitário e solidário, orientando-se por uma cultura pela vida e reconhecendo a interdependência entre os habitantes do Planeta:

A escuta da voz, antes sufocada, dos povos indígenas originários permitiu que sua alma se expressasse na Constituição, e pela via democrática, seus sentimentos mais profundos e seu modo de viver ganhassem forma jurídica com a constitucionalização do Bem Viver no Equador (Sumak Kawsay) e na Bolívia (Suma qamaña), inclusive com o reconhecimento dos direitos de 
Pachamama (da natureza), marco a partir do qual se inaugura no mundo, no âmbito jurídico, o giro ecocêntrico (MORAES, 2014, p. 177).

Neste novo arranjo constitucional, no cenário latino-americano, mais especificamente no Equador e na Bolívia, surge a voz dos povos indígenas, protagonizando a função de agentes transformadores, reivindicando seus direitos e promovendo mudanças institucionais pautadas nos ideais do Bem Viver. Neste marco, promovem a superação do modelo de EstadoNação e avançam na consolidação do Estado Plurinacional.

Um aspecto que merece ser destacado é o protagonismo indígena no desenvolvimento das primeiras ideias sobre o Bem Viver que se consolidaram nas constituições da Bolívia e do Equador. Nesse sentido, Le Quang e Vercoutère (2013, p. 10) ressaltam:

Os povos indígenas, ponta de lança na luta contra o neoliberalismo encarnado pelas instituições financeiras internacionais e pelas políticas nacionais de governos corruptos, aparecem como fontes legítimas de alternativas ao sistema econômico e aos modos de vida que conduziram à crise global. (tradução livre).

$\mathrm{O}$ ativismo dos povos indígenas vem contribuindo para novos arranjos no campo constitucional, encorajando e impulsionando a criação de um constitucionalismo emancipador, pois abre espaço para a participação dos cidadãos, em busca da construção de uma identidade legítima latino-americana, propondo o rompimento com o colonialismo constitucional, dialogando com sabedorias múltiplas, respeitando a diversidade e os direitos coletivos. A constitucionalização do Bem Viver representa, assim, a instituição de um pacto social baseado na democracia intercultural para toda a América Latina (CAOVILLA, 2016).

No Equador, o Bem Viver, do quéchua, Sumak Kawsay, foi constitucionalizado em 2008, com a instituição de um conjunto de "direitos do Bem-Viver" que se encontram no mesmo patamar hierárquico de outros princípios como os relacionados à natureza, à liberdade, à participação, aos povos e nacionalidades. Entre os "direitos do Bem-Viver" pode-se citar saúde, educação, habitação, água, alimentação e comunicação.

Além disso, a Constituição Equatoriana de 2008 institui um novo modelo Estado profundamente inclusivo, com o reconhecimento da existência de uma multiplicidade de nacionalidades, culturas, línguas, religiões e espiritualidades. Esse Estado, também, incorpora as formas comunitárias de organização e autoridade. Assim, representa uma nova 
possibilidade epistemológica que dá condições, especialmente aos povos indígenas, de recuperar autonomia e soberania com mecanismos de participação e representação perante o Estado, com base na democracia comunitária.

Em 2009 a Bolívia, por sua vez, constitucionalizou o Suma Qamaña, em aymara, ou Viver Bem, enquanto princípio ético-moral e base fundamental do Estado:

Artigo 8:

I. O Estado assume e promove como princípios ético-morais da sociedade plural: ama qhilla, ama llulla, ama suwa (não sejas frouxo, não sejas mentiroso nem sejas ladrão), suma qamaña (viver bem), ñandereko (vida harmoniosa), teko kavi (vida boa), ivi maraei (terra sem mal) y qhapaj ñan (caminho ou vida nobre).

II. O Estado se fundamenta nos valores da unidade, igualdade, inclusão, dignidade, liberdade, solidariedade, reciprocidade, respeito, complementaridade, harmonia, transparência, equilíbrio, igualdade de oportunidades, equidade social e de gênero na participação, bem estar comum, responsabilidade, justiça social, distribuição e redistribuição dos produtos e bens sociais, para viver bem. (BOLÍVIA, 2009). (tradução livre).

No intuito de efetivar o Bem Viver em suas múltiplas dimensões, a Constituição Boliviana, em seu artigo 313, comprometeu-se com a geração de produto social, produção, distribuição e redistribuição justa da riqueza, redução das desigualdades regionais e de acesso aos recursos produtivos, entre outros e, assim, embora não explicitamente, reconheceu o Suma Qamaña como uma das finalidades do Estado (GUDYNAS, 2011).

Esta mudança, positivada na Constituição Boliviana de 2009, é resultado da luta dos povos marginalizados que constituem a base social e desejam construir alternativas próprias de superação dos paradigmas eurocêntricos, tanto cultural como epistemologicamente.

É possível perceber, portanto, as diferenças nas propostas de constitucionalização do Sumak Kawsay ou Suma Qamaña, no Equador e na Bolívia, respectivamente, mas também é preciso destacar que o Bem Viver traz em si essa pluralidade, sendo ajustável à realidade socioambiental de cada comunidade que compartilhe o propósito de dar voz às culturas silenciadas e criar alternativas às práticas políticas e jurídicas monistas e eurocêntricas que por muito tempo, desde a colonização, predominaram e perpetuaram a colonialidade do ser, do saber e do poder na América Latina.

Neste horizonte, os povos indígenas, procuram reconstituir o poder político, jurídico e econômico, e essencialmente procuram delinear ao mundo novas formas viáveis e solidárias para uma sociedade crescentemente democrática, para que o ideal de um mundo melhor possa começar a ser delineado, a partir da América Latina. 
Com esta proposta emancipatória, os povos indígenas não são mais considerados sob o manto da tutela estatal, são definidos como sujeitos políticos, povos com direitos à autodeterminação e autonomia nos seus valores, crenças e tradições. O monismo jurídico abre espaço para a inclusão constitucional das manifestações das comunidades indígenas em suas diferenças, realidades e práticas sociais, legitimando a participação das comunidades indígenas nas instituições estatais e no sistema de justiça comunitária.

\section{Por uma educação jurídica intercultural para o Bem Viver - remando na contramão da dominação}

Construir outro modelo de sociedade, inspirados na sabedoria indígena e na cultura do Bem Viver é um ideal a ser alcançado, que aos poucos vai sendo delineado e acolhido, traduzindo-se em esperança no marco das Constituições Boliviana e Equatoriana, que expressam a vontade latino-americana de uma nova produção epistemológica que questiona as antigas formas de poder (colonialidade do poder, do ser e do saber), construída à luz da modernidade/colonialidade (CAOVILLA, 2016, p. 162).

Tal intencionalidade mostra sinais de que é possível promover um projeto de descolonização da América Latina, na medida em que reconhece a autonomia dos povos indígenas, sua identidade, cultura, ancestralidade, diversidade, permitindo-lhes escrever sua própria história em harmonia com a natureza, valorizando a cosmologia indígena do Bem Viver, reconhecendo o ser humano como parte integrante da natureza, como todos os outros seres vivos do planeta.

A partir das utopias dos povos do Equador e da Bolívia e das reformas constitucionais havidas, evidenciam-se possibilidades de uma mudança civilizatória e, nesse contexto, a educação ocupa um lugar privilegiado quanto aos processos de transformação, abandonando sua função reprodutora, para contribuir com a gestação de um mundo mais justo e democrático, no qual cada ser humano seja mais humano, construindo-se uma educação transformadora, uma educação para o Bem Viver, ante a possibilidade de que todo processo educativo se faça das sabedorias múltiplas, das capacidades criativas, expressivas e reflexivas, que compõem o mosaico latino-americano (CAOVILLA, 2016).

Essas sabedorias foram e ainda são sistematicamente censuradas, desprezadas, subalternizadas pelo sistema educativo tradicional, conformado no cientificismo. Para tanto, aposta-se na pesquisa, no ensino e na extensão comunitária como possibilidade de resgatar, 
ressignificar e reintegrar as práticas daqueles considerados "outros", valorizando a sua existência no mundo.

Deve-se reexaminar o Direito, não como ordem estagnada, mas como positivação em luta, dos princípios libertadores, na totalidade social em movimento. O Direito, então, deve ser visto como processo histórico, não como coisa feita, perfeita e acabada; é aquele vir a ser que se enriquece nos movimentos de libertação das classes e grupos ascendentes e que definha nas explorações e opressões que o contradizem, mas de cujas próprias contradições brotarão as suas conquistas. Eis o que desafia o Direito: repensar seus próprios conceitos, práticas, valores e paradigmas, para que emancipe as vítimas sofredoras, excluídas, subordinadas, principalmente nas humanidades latino-americanas periféricas (LYRA FILHO, 1982)

Trata-se de operacionalizar uma formulação de alcance teórico-prático que permita o profundo questionamento e da desmontagem das formas hegemônicas de saber e de representação social que têm mantido a cultura da dominação. Impõe-se, assim, explicitar a natureza da libertação que se propõe e, posteriormente, fazer a opção, apontar e trazer subsídios para articular uma 'teoria crítica' capaz de contribuir para se repensar uma cultura político-jurídica na perspectiva latino-americana (WOLKMER, 2004, p. 6).

De acordo com Wolkmer, o pluralismo jurídico mostra-se capaz de aproximar a produção do Direito da sociedade, contribuindo para a concretização de uma sociedade mais justa e igualitária:

Torna-se imperativo que o pluralismo como novo referencial do político e do jurídico esteja necessariamente comprometido com a atuação de novos sujeitos coletivos (legitimidade de autores), com a satisfação das necessidades humanas essenciais ('fundamentos materiais') e com o processo político democrático de descentralização, participação e controle comunitário (estratégia). Soma-se ainda a inserção do pluralismo jurídico com certos 'fundamentos formais' com a materialização de uma 'ética concreta da alteridade' e a construção de processos atinentes a uma 'racionalidade emancipatória', ambas capazes de traduzir a diversidade e a diferença das formas de vida cotidiana, a identidade, informalidade e autonomia dos agentes legitimadores (WOLKMER, 2001, p. 233-234).

Para Caovilla (2016), faz-se necessária uma nova proposta educativa no âmbito jurídico, que se comprometa em relacionar o passado com o presente, de modo a resistir criticamente às formas de opressão, de violência e de exclusão gestadas nas relações de dominação e de desigualdade sistemáticas que vêm sendo vivenciadas ao longo da história. 
Propõe-se uma concepção de educação jurídica, tendo em conta o legado da educação de Paulo Freire, somada a proposta da Filosofia da Libertação, de Enrique Dussel, e do Pluralismo Jurídico, de Antonio Carlos Wolkmer, numa perspectiva crítica capaz de transcender o modelo epistemológico universal dos europeus, que inspiraram o Direito na América Latina, pois [...] aprender o que é Direito nas 'obras' da ideologia dominante só poderia, evidentemente, servir para um dos dois fins: ou beijar o chicote com que apanhamos ou vibrá-lo no lombo dos mais pobres, como nos mande qualquer ditadura (LYRA FILHO, 1982).

A ciência do Direito, no contexto de colonialidade, sustentou-se na manutenção de uma estrutura social excludente e opressora, que naturalizou desigualdades:

[...] a ciência moderna colonizou as outras formas de racionalidade, destruindo assim o equilíbrio dinâmico entre regulação e emancipação, em detrimento desta, o êxito da luta contra os monopólios de interpretação acabou por dar lugar a um novo inimigo, tão temível quanto o anterior, e que a ciência moderna não podia senão ignorar: a renúncia à interpretação, renúncia paradigmaticamente patente no utopismo automático e também na ideologia e na prática consumistas. [...] o cientificismo e o estatismo moldaram o direito de forma a convertê-lo numa utopia automática de regulação social, uma utopia isomórfica da utopia automática da tecnologia que a ciência moderna criara. Quer isto dizer que, embora a modernidade considerasse o direito um princípio secundário (e talvez provisório) de pacificação social relativamente à ciência, uma vez submetido ao Estado capitalista o direito acabou por se transformar num artefacto científico de primeira ordem. (SANTOS, 2000, p. 144).

Para Paulo Freire, a libertação dos oprimidos, tão necessária a si e ao opressor, será possível mediante uma nova concepção de educação: a educação libertadora, aquela que vai remar na contramão da dominação.

Para descolonizar o conhecimento jurídico é preciso dar voz ao oprimido abrir-se à construção de epistemologias plurais, num diálogo horizontal entre os saberes, para promover a emancipação social, o que elevará os marginalizados à condição de protagonistas (CAOVILLA, 2016, p. 102-103).

Com a ascensão do movimento de tendência teórico-crítica do constitucionalismo latino-americano, uma proposta que se contrapõe à matriz teórica eurocêntrica, surge a possibilidade de uma nova reflexão jurídica, cultural e social, voltada justamente ao debate sobre a alteridade, incluindo temas como: diferenças, diversidade, processos de exclusão social, consolidação de uma nova cidadania e de uma outra sociedade voltada para 
compreensão das pessoas, de grupos de pessoas e comunidades em seus espaços sociais, culturais e ambiente natural, mas também voltada ao respeito às suas identidades, personalidades e opções de vida.

O constitucionalismo latino-americano inaugura uma nova etapa, fazendo emergir as bases para uma outra leitura do mundo: a plural, cujo manancial não parte do Estado e sim da voz dos oprimidos, dos novos atores, dos sujeitos sociais. É nessa luta por um outro Direito que será gestada uma outra educação; uma educação feita com utopia, esperança, sonhos, mas também com indignação (CAOVILLA, 2016, p. 290).

Com base no pluralismo jurídico comunitário-participativo, propõe-se outra concepção de ensino jurídico, lançando mão de uma educação jurídica para o "bem viver", como estratégia de empoderamento das indivíduos, especialmente em contextos de exclusão extrema, como vivenciado no Brasil e em toda a América Latina (CAOVILLA, 2016).

O intento é superar os muros de uma cultura jurídica individualista, no contexto da formação e atuação dos profissionais da área jurídica, avançando no reconhecimento das práticas plurais, comprometidas com propostas libertadoras, capazes de romper com as desigualdades, a opressão e a subalternidade.

Uma educação plural, intercultural e interdisciplinar à compreensão dos problemas sociais, propõe não somente a emancipação e a autonomia dos indivíduos, visando uma mudança de orientação epistemológica, de forma a renovar a teoria crítica do Direito com a criação de escolas de Direito, que tenham entre as suas finalidades, o enfrentamento dos problemas da sociedade, o reconhecimento às diferenças, à pobreza, à marginalidade, mas também a abertura para inclusão de outras "espécies como sujeitos de direitos". Aqui a mudança de paradigma é o fio condutor de toda a transformação, nesse sentido, o Equador, em uma prática vanguardista em matéria ambiental, promove a libertação da natureza da condição de simples objeto de propriedade, reconhecendo-a como um sujeito de direito (CAOVILLA, 2016, p. 171). O ser humano, portanto, passa a ser integrante da natureza e não mais o centro dela.

\section{Considerações finais}

A construção de um pensamento descolonial que seja capaz de produzir conhecimento jurídico a partir das problemáticas do Sul, que supere a cultura jurídica ocidental, antropocêntrica, é um grande desafio a ser enfrentado. 
O novo marco civilizatório que despontou dos Andes neste início do século XXI, fundamentado no constitucionalismo latino-americano, reafirma princípios do pluralismo jurídico, da interculturalidade, da dignidade humana, ancorados numa visão contrahegemônica da educação, que poderão dar ensejo a grandes transformações, sendo possível imaginar uma educação intercultural, que abandona a perspectiva epistêmica subalterna e antropocêntrica, valorizando culturas, identidades, saberes, num sistema de valores centrado na natureza, a partir de uma ética ecocêntrica.

Esta perspectiva crítica da colonialidade e das relações de poder, reforça a importância de desenvolver uma proposta de educação jurídica intercultural, capaz de promover a descolonização do ser, do saber e do poder no contexto latino-americano, contestando a lógica tradicional do ensino e da educação transmissiva, em especial ao modelo de ensino jurídico, fundamentado na efetivação da cidadania, da democracia e de uma justiça para o bem viver, descortinando um novo caminho à educação jurídica na América Latina, com o propósito de renovar o processo de construção dos saberes, embasado no pluralismo jurídico comunitárioparticipativo, na tentativa de uma profunda transformação social, pela educação.

\section{Referências}

ACSELRAD, Henri. Justiça ambiental. In: SIDEKUN, Antonio; WOLKMER, Antonio Carlos; RADAELLI, Samuel Manica (Org.). Enciclopédia Latino-Americana de Direitos Humanos. Nova Petrópolis: Nova Harmonia, 2016, p. 500-507.

BOFF, Leonardo. Constitucionalismo ecológico na América Latina. 2013. Disponível em: http://leonardoboff.wordpress.com. Acesso em: 20 mar. 2018.

BOLÍVIA. Constitución politica del Estado. 2009. Disponível em: http://pdba.georgetown.edu/Constitutions/Bolivia/bolivia09.html. Acesso em: 11 out. 2017.

CAOVILLA, Maria Aparecida Lucca. Descolonizar o direito na América Latina: o modelo do pluralismo e a cultura do bem viver. Chapecó: Argos, 2016.

; WENGENOVICZ, Tais. Bem Viver e Interculturalidade: Por Outra Epistemologia no Direito. In: IV Seminario Internacional Culturas, Desarrollos y Educaciones SICDCES, 2018, Santiago. Memorias del IV Seminario Internacional Culturas, Desarrollos y Educaciones (SICDES). Migraciones, Interculturalidad y buen vivir: diálogos y resistencias. Chapecó, SC: Argos Editora, 2018. v. 1. p. 33-41.

CARDUCCI, Michele; AYMARA, Lídia Patrícia Castillo. Nuevo Contitucionalismo de la biodiversidad vs. Neoconstitucionalismo del riesgo. Revista Sequência. Florianópolis, n. 73, ago. 2016. Disponível em: https://periodicos.ufsc.br/index.php/sequencia/article/view/21777055.2016v37n73p255/33566\&gt. Acesso em: 29 nov. 2017. 
CASTRO-GÓMEZ, Santiago. Ciências sociais, violência epistêmica e o problema da “invenção do outro". In: LANDER, Edgardo (Org.). A Colonialidade do Saber: eurocentrismo e ciências sociais, perspectivas latino-americanas. Buenos Aires: CLACSO, 2005 .

DUSSEL, Enrique. Ética da libertação na idade da globalização e da exclusão. PetrópolisRJ: Vozes, 2002.

EQUADOR. Constitución Politica de La República del Ecuador. 2008. Disponível em: http://pdba.georgetown.edu/Constitutions/constudies.html. Acesso em: 15 out. 2018.

FAJARDO, Raquel Yrigoyen. Constitucionalismo pluralista. In: SIDEKUN, Antonio; WOLKMER, Antonio Carlos; RADAELLI, Samuel Manica (Orgs.). Enciclopédia LatinoAmericana de Direitos Humanos. Nova Petrópolis: Nova Harmonia, 2016.

FANON, Frantz. Os condenados da terra. Rio de Janeiro: Civilização Brasileira, 1968.

FREIRE, Paulo. Pedagogia da autonomia: saberes necessários à prática docente. São Paulo: Paz e Terra, 2003.

GALEANO, Eduardo. As veias abertas da América Latina. Tradução de Sergio Faraco. Porto Alegre: L\&PM Pocket, 2010.

GARCIA, Denise Schmitt Siqueira; GARCIA, Heloise Siqueira. Governança Ambiental Global como Critério Regulador e Garantidor da Justiça Ambiental. Revista de Direito, Governança e Novas Tecnologias, Curitiba. v. 2, n. 2. p. 1-17. jul/dez, 2016. Disponível em: http://www.indexlaw.org/index.php/revistadgnt/article/view/1481. Acesso em: 01 jun. 2018.

GUDYNAS, Eduardo. Bem-Viver: Germinando alternativas ao desenvolvimento. América Latina em Movimento-ALAI, v. 462, n. 1-20, 2011. Disponível em: http://loomioattachments.s3.amazonaws.com/uploads/4b8f3b4112dd1e775500bced50f5747b/bem-viver_germinando-alternativas-ao-desenvolvimento.pdf. Acesso em: 10 out. 2017.

HERCULANO, Selene. O clamor por justiça ambiental e contra o racismo ambiental. revista de Gestão Integrada em Saúde do Trabalho e Meio Ambiente. v.3, n.1. jan./ abril 2008. Disponível em: http://www3.sp.senac.br/hotsites/blogs/InterfacEHS/wpcontent/uploads/2013/07/art-2-2008-6.pdf. Acesso em: 01 jun. 2018.

LARREA, Ana María. La disputa de sentidos por el buen vivir como processo contraehemónico. In: LARREA, Ana María (Org.). Los nuevos retos de América Latina: Socialismo y Sumak Kawsay. Quíto: SENPLADES, 2010.

LE QUANG, Mathieu; VERCOUTÈRE. Ecosocialismo y Buen Vivir. Diálogo entre dos alternativas al capitalismo. 1 $^{\mathrm{a}} \mathrm{ed}$. Quito: Editorial IAEN, 2013.

MORAES, Germana de Oliveira. Pelos Direitos de Pachama e pelo Bem Viver: um modelo socioambiental ecocêntrico, comunitário e solidário. In: FILHO, Carlos Frederico Marés de Souza; NOGUEIRA, Caroline Barbosa Contente; FERREIRA, Heline Sivini. (orgs). Direito 
Socioambiental: uma questão para a América Latina (Livro digital). Curitiba: Letra da Lei, 2014.

MIGNOLO, Walter. Desobediência epistêmica: a opção descolonial e o significado de identidade em política. Cadernos de Letras da UFF - Dossiê: Literatura, língua e identidade, n. 34, p. 287-324, 2008. Disponível em:

http://www.uff.br/cadernosdeletrasuff/34/traducao.pdf. Acesso em: 01 jun. 2018.

PORTO-GONÇALVES, Carlos Walter. Apresentação da edição em português. In: LANDER, Edgardo (Org). A colonialidade do saber: ecocentrismo e ciências sociais. Perspectivas latino-americanas. Buenos Aires: Clacso, 2005. P.19-20.

QUIJANO, Anibal. Colonialidade do Poder, Eurocentrismo e América Latina. In: LEHER, Roberto \& SETÚBAL, Mariana (Org.). Pensamento crítico e movimentos sociais: diálogos para uma nova práxis. Buenos Aires: CLACSO, 2005.

SANTOS, Boaventura de Souza. Refunddación del estado en América Latina. Perspectivas desde una epistemología del Sur. La Paz: Plural, 2010b.

Cortez, 2000.

. A crítica da razão indolente: contra o desperdício da experiência. 3. ed. São Paulo:

. MENESES, Maria Paula (Org.). Epistemologias do sul. Coimbra: Almedina, 2009.

. A universidade do século XXI: para uma reforma democrática e emancipatória da universidade. São Paulo: Cortez, 2004.

SIDEKUM, Antonio; WOLKMER, Antonio Carlos; RADAELLI, Samuel Manica.

Enciclopédia latinoamericana dos direitos humanos. Nova Petrópolis: Nova Harmonia, 2016.

TLOSTANOVA, Madina; MIGNOLO, Walter. Global Coloniality and the Decolonial Option. Kult 6 Special Issue. 2009. Disponível em:

http://postkolonial.dk/artikler/kult_6/MIGNOLO-TLOSTANOVA.pdf. Acesso em: 01 jun. 2018.

WALSH, Catherine. Interculturalidad y colonialidad del poder. Un pensamento y posicionamento otro desde la diferencia colonial. In: Castro-Gómez, S.; Grosfoguel, R. (Ed.). El giro decolonial. Reflexiones para una diversidad epistémica en el capitalismo global.

Bogotá: Siglo del Hombre (2007). Disponível em:

http://catherine-walsh.blogspot.com/2010/11/\%20interculturalidad-y-colonialidad-del.html. Acesso em: 14 dez. 2018.

WOLKMER, Antonio Carlos (Org.). Direitos Humanos e filosofia jurídica na América Latina. Rio de Janeiro: Lumen Juris, 2004.

. Pluralismo jurídico: fundamentos de uma nova cultura no direito. 3. ed. São Paulo: Alfa-Ômega, 2001. 


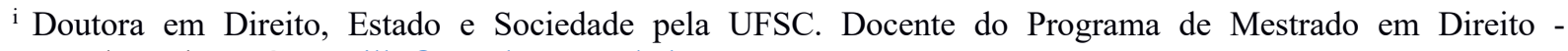
PPGD/Unochapecó. caovilla@unochapeco.edu.br

ii Pesquisador do Grupo de Pesquisa Direitos Humanos e Cidadania/Unochapecó.

$\underline{\text { mb manoel@unochapeco.edu.br }}$

iii Mestranda do PPGD/Unochapecó. Pesquisadora do Grupo de Pesquisa: Direitos Humanos e Cidadania/Unochapecó. (carmelice@,unochapeco.edu.br) 